\title{
Human papillomavirus in Italy: retrospective cohort analysis and preliminary vaccination effect from real-world data
}

\author{
A. Marcellusi ${ }^{1,2} \oplus$. F. S. Mennini ${ }^{1,2} \cdot$ P. Sciattella ${ }^{1} \cdot$ G. Favato $^{2}$
}

Received: 26 May 2020 / Accepted: 1 May 2021 / Published online: 12 June 2021

(C) The Author(s) 2021

\begin{abstract}
Introduction The objective of this study was to estimate the lifetime risk of hospitalization associated with all major human papillomavirus (HPV)-related diseases in Italy. Moreover, a preliminary vaccination effect was also performed.

Methods A retrospective, nonrandomized, observational study was developed based on patients hospitalized between 2006 and 2018 in Italy. All hospitalizations were identified through administrative archives, according to the International Classification of Diseases (ICD-9 CM). Information related to the hospital discharges of all accredited public and private hospitals, both for ordinary and day care regimes, was taken into account. We included hospitalizations related to resident patients presenting one of the ICD-9-CM codes as primary or secondary diagnosis: genital warts (GW); 'cervical intraepithelial neoplasia (CIN)' (067.32-067.33); 'condyloma acuminatum' (078.11); 'anal cancers' (AC) (154.2-154.8); oropharyngeal cancers (OC): 'oropharyngeal cancer'(146.0-146.9) and 'head, face and neck cancers' (171.0); genital cancers (GC): 'penis cancer' (187.1-187.9) and 'cervical cancer' (180.0-180.9). Data were stratified by birth year and divided into two groups: (a) cohort born before 1996 (not vaccinable) and (b) cohort born after 1997 (vaccinable-first cohort that could be vaccinated at the beginning of immunization schedule in girls since 2008 in Italy). Disease-specific hospitalization risks for both groups were estimated by sex, year and age.

Results Epidemiological data demonstrate that the peak hospitalization risk occurred at 24-26 years of age for GW (both male and female); 33-41 and 47-54 years for AC males and females, respectively; 53-59 and 52-58 years for OC males and females, respectively; and 54-60 and 39-46 years for GC males and females, respectively. Focusing on GW and GC, vaccinable females demonstrate a significant reduction in hospitalization risks ( $-54 \%$ on average) compared to nonvaccinable females until 21 years of age (maximum follow-up available for girls born after 1997). Comparing the same birth cohort of males, no differences in hospitalization risk were found.

Conclusions These results support the importance of primary prevention strategies in Italy and suggest that increased VCRs and time of observation (genital cancers for which vaccination is highly effective, have a latency of some decades) will provide useful information for decision-makers.
\end{abstract}

Keywords Human papillomavirus $\cdot$ Real-world data $\cdot$ Hospitalization $\cdot$ Public health prevention

JEL Classification I18 · Government policy $\cdot$ Regulation $\cdot$ Public health

\section{Introduction}

A. Marcellusi

a.marcellusi@kingston.ac.uk

1 Economic Evaluation and HTA (EEHTA), CEIS, Faculty of Economics, University of Rome "Tor Vergata”, Rome, Italy

2 Institute for Leadership and Management in Health, Kingston University London, London, UK
Human papillomavirus (HPV) is the most common sexually transmitted virus and causes a substantial burden of disease in both men and women [1]. In 2013-2014, approximately $45 \%$ of men and $40 \%$ of women between the ages of 18 and 59 had genital HPV infection [2], a large proportion of which is preventable with vaccination.

Since the first prophylactic vaccine against Human Papillomavirus (HPV) was licensed in 2006, the quadrivalent 
vaccine (which protects against high-risk HPV types 16 and 18 , and low-risk types 6 and 11, which cause $90 \%$ of genital warts) or bivalent vaccine (targeting HPV types 16 and 18) have been implemented in more than 28 countries as part of their national immunization programmes [3]. In December 2014, a nonavalent vaccine (9vHPV), developed r. The 9vHPV gained marketing authorisation from the European Commission, valid throughout the European Union, in June 2015.

The HPV vaccine has been shown to be close to $100 \%$ effective against benign external anogenital warts (GWs) [4] and against persistent infection with HPV16 and 18 [5], which are responsible for $70 \%$ of all cervical cancers [6]. HPV also accounts for a smaller fraction of cancers of the vulva, vagina, anus, penis, head, and neck [7]. The low-risk HPV variants of genotypes 6 and 11 are responsible for approximately $90 \%$ of benign external anogenital warts [8] and almost all cases of recurrent respiratory papillomatosis (RRP) [9, 10].

At the beginning, the vaccination was mainly targeted at girls between the ages of 9 and 12 years, before the onset of sexual activity by females; however, various countries have also implemented gender neutral primary prevention strategies enrolling for boys at the same age [11].

Primary prevention of HPV-related diseases in Italy started in 2008, and the vaccination programme consists of active and free service for all 12-year-old girls. Moreover, in 2017, the Italian Ministry of Health extended the immunization programme to 12-year-old boys, even though some regions had already started in 2014 [12]. Although different studies were conducted in Italy to evaluate the epidemiological impact [13, 14], economic burden [15-17], and vaccination cost-effectiveness [11, 18-22] of HPV-related diseases, no specific analyses were conducted from a cohort real-world data perspective.

The objective of this study is to estimate the lifetime risk of hospitalization and direct costs associated with human papillomavirus (HPV)-related disease in Italy. Moreover, a preliminary vaccination effect was also performed.

\section{Methods}

A retrospective, nonrandomised, observational study was developed based on patients hospitalized between 2006 and 2018 in Italy. All hospitalisations were identified through administrative archives, according to the International Classification of Diseases (ICD-9 CM). Information related to the hospital discharges of all accredited public and private hospitals, both for ordinary and day care regimes, was taken into account. We included hospitalisations related to resident patients presenting one of the ICD-9-CM codes as primary or secondary diagnosis: genital warts $(\mathrm{GW})$ : 'condyloma acuminatum' (078.11); 'cervical intraepithelial neoplasia (CIN)' (067.32-067.33); 'anal cancers' (AC) (154.2-154.8); 'oropharyngeal cancers (OC): 'oropharyngeal cancer' (146.0-146.9) and 'head, face and neck cancers' (171.0); and genital cancers (GC): 'penis cancer' (187.1-187.9) and 'cervical cancer' (180.0-180.9) [16, 17]. A sensitivity analysis was applied considering only the primary diagnosis.

Overall hospitalization rates were calculated as the ratio between the number of hospitalisations at each age of the cohort and the number of residents in Italy with the same age and for the same cohort [23]. Data were then stratified by birth years, age of hospitalization, and ICD-9-CM group.

Given the highest incidence rate of GW and CIN among young people [24] and their short latency after HPV infection, a focus was made on this condition among females. The GW and CIN female cohort was divided into two groups: (a) a cohort born before 1996 (not vaccinable) and (b) a cohort born after 1997 (vaccinable- the first cohort that was offered vaccination starting from 2008). The contemporary rates were estimated by year, age, and sex for both hospitalization and patients. For other demographic analyses, the ideal aim of this work would represent a generation of individuals hospitalized through time in Italy and measure the probabilities of hospitalization and costs occurring in each generation at different ages until the whole cohort became extinct [25]. However, the limited number of years covered with national data (11 years for each cohort) cannot cover the entire lifespan of the cohort, and it is not possible to calculate the age-specific probabilities of hospitalization calculated using observed hospitalization (or patients hospitalized) data from the cohort. For this reason, a hypothetical cohort of 250,000 boys and girls was simulated, assuming that the hospitalization risk of a single generation at every age corresponds to the average risk estimated on different contemporary cohorts [26].

The total costs related to hospitalisations were calculated using the DRGs (with 2013 values) of hospitalized patients based on their age, gender and consumption of resources during their hospital stay. Information related to the hospital discharges (HDRs) of all accredited public and private hospitals in Italy, both for ordinary and day care regimens, was included to estimate the costs of cervical, vulvar, vaginal, penile, head, and neck cancer. Hospitalization and lifetime costs for these HPV-related conditions were investigated indepth in previous work [17].

To combine real-world data and the analysis of the two hypothetical cohorts, the overall hospitalization rates for each disease were multiplied to a hypothetical 250,000 women and 250,000 men lived at each age of the cohort. The number of hospitalization by age was multiplied by the average hospitalization costs for each age estimated by the DRGs tariff. Finally, a simple forecast analysis for CIN and GW by age was simulated considering the average observed 
reduction of hospitalization rates for vaccinable cohort vs not vaccinable patients between 17 and 21 years old. Cost and risk reduction were estimated as absolute and percentage difference, respectively.

\section{Results}

Our results covered 3 areas: (i) hospitalization rates and cost by life birth, sex, and HPV-related condition; (ii) hospitalization rate reduction per GW among women vaccinated and not vaccinated; and (iii) lifetime direct cost savings given the observed drop in hospitalization rate for GWs.

Figure 1 shows the hospitalization rate by age of a hypothetical cohort of 250,000 girls or boys born, close to the yearly natality observed in Italy. CIN, GW, and GC hospitalization rates are most frequent for women, with peaks between 20 and 27 and 48 and 58 years of age, respectively. A higher risk for men was registered for OC, with a peak between 58 and 68 years. Similar risks for both sexes were registered for AC. If we considered principal diagnosis as inclusion criteria, on average $81 \%, 68 \%$, and $61 \%$ of the overall hospitalization were registered for $\mathrm{GW}$ in men, $\mathrm{GW}$ women, and CIN, respectively (orange line of Fig. 1). A lower percentage of principal diagnosis were registered for cancers $(46 \%, 41 \%$, and $56 \%$ on average for AC, OC, and $\mathrm{GC}$, respectively).

A total lifetime cost of $€ 51.4$ million was estimated for hospitalization cost in Italy (67\% of which related to OC and GC-Table 1 section a). A total of $66 \%$ of the overall hospitalization costs are associated with women's diseases ( $€ 33.9$ million), and the most relevant economic burden was attributed to GC for women (54\% of the total women hospitalization cost) and OC for men (58\% of the total men hospitalization cost). Considering hospitalization with a primary diagnosis as the only inclusion criteria, the overall costs decrease to $€ 29.2$ million ( $-43 \%$ of the overall costs). In this secondary analysis, the overall costs associated with women decrease to 59\%, while the overall distribution of the economic burden between the diseases remain constant (Table 2 section $b$ ).

Focusing on GW and CIN for women, Fig. 2 shows the hospitalization risks for two hypothetical cohorts of 250,000 women who follow the rate registered for the women (a) born before 1996 (not vaccinable) and (b) born after 1997 (vaccinable-the first cohort that was offered vaccination starting from 2008). The vaccinable cohort registered lower hospitalization rates for all comparable ages, with an average reduction of $61 \%$ and $67 \%$ between 17 and 21 years old for GW and CIN, respectively (Fig. 2a). Figure 2b, instead, shows the observed hospitalization age-specific rates for the not vaccinable cohort and the hypothetical risk reduction for vaccinated women after 21 years (the last age in which vaccination can be assumed), projecting constant average risk reduction over the lifetime span.

GW observed hospitalization cost reduction for the vaccinable cohort corresponds to $-€ 305,265$ ( $-62 \%$ of the overall cost) compared with not vaccinable cohort. These reductions increase to $€ 1.6$ million if the same reduction rate is applied to the lifetime cost (Table 2).

\section{Discussion}

The purpose of this study was to estimate the lifetime risk of hospitalization and direct costs associated with human papillomavirus (HPV)-related disease in Italy. Moreover, a preliminary vaccination effect was also performed.

Our study adopted a real-world data approach to estimate lifetime hospitalization risk and costs and conducted a very preliminary assumption on estimating the actual cost reduction attributable to the vaccination strategy in Italy considering the most recent data available. Additionally, we included a lifetime cost reduction scenario for GW in women, assuming that the observed risk and cost reduction remain constant over the observed ages in vaccinable women. Therefore, the present study was the first to measure the lifetime economic burden of HPV-related diseases in Italy considering a longitudinal perspective with newly available administrative data. By estimating the resource consumption attributable to the different cohorts, we aim to predict the effects of the strategies adopted in Italy at the beginning of vaccination introduction and to inform future public health decisions.

According to the results of this study, the hospitalization risk profile by age demonstrates the high impact of cancer condition for adult patients (two-thirds of the overall hospitalization occurs after 50 years), while GW and CIN hospitalization occurs for young adults (half of the total hospitalization before 38 years of the observed women). Furthermore, the economic burden among men represented more than one-third (34\%) of the total hospitalization cost associated with the HPV-related diseases analyzed, which is consistent with previously published data $[8,17,27]$ and with the effort to extend the anti-HPV immunization programme to include boys in the National Immunization Plan 2017-19.

Moreover, hospitalization rates were consistent with the epidemiological profile of women in Italy [13, 28-30], while the cost results represent, to our knowledge, the first and original data in the national and international literature. Indeed, this study estimated that considering a hypothetical cohort of 250,000 men and 250,000 women (on average, the number of live births in the last decade in Italy), we can expect a total hospitalization cost of $€ 51$ million.

Analyzing GW and CIN for women, our study demonstrates that the hospitalization risks for women born before 

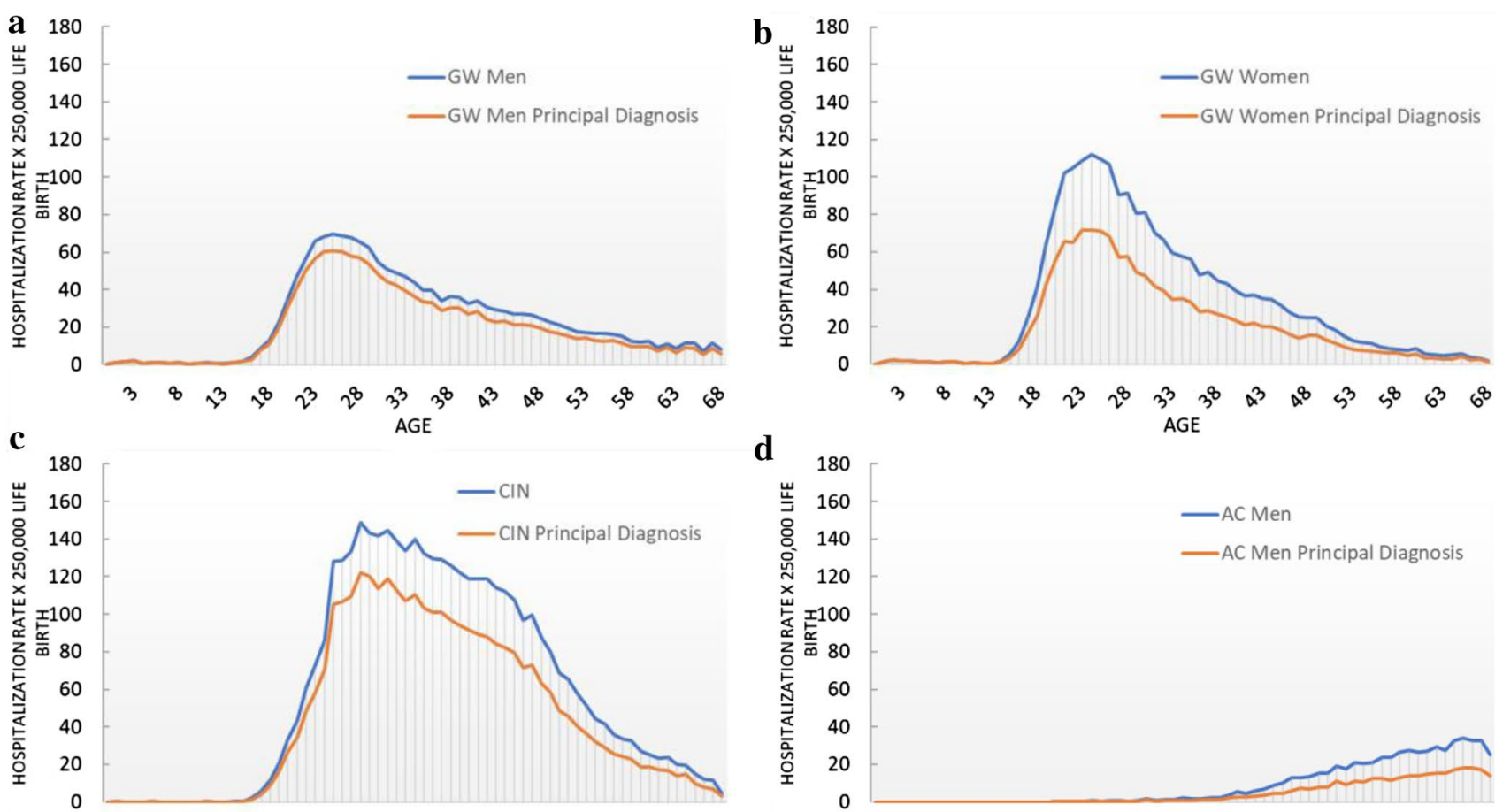

d

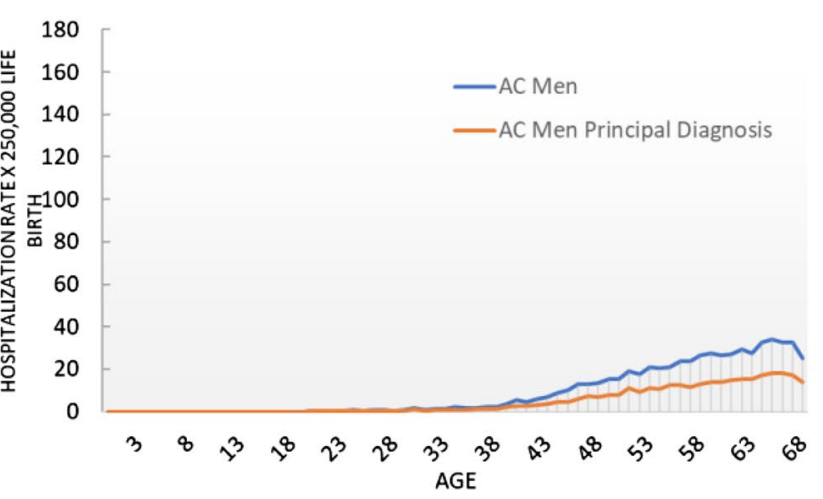

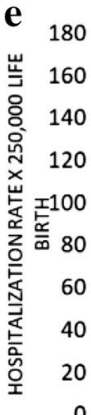
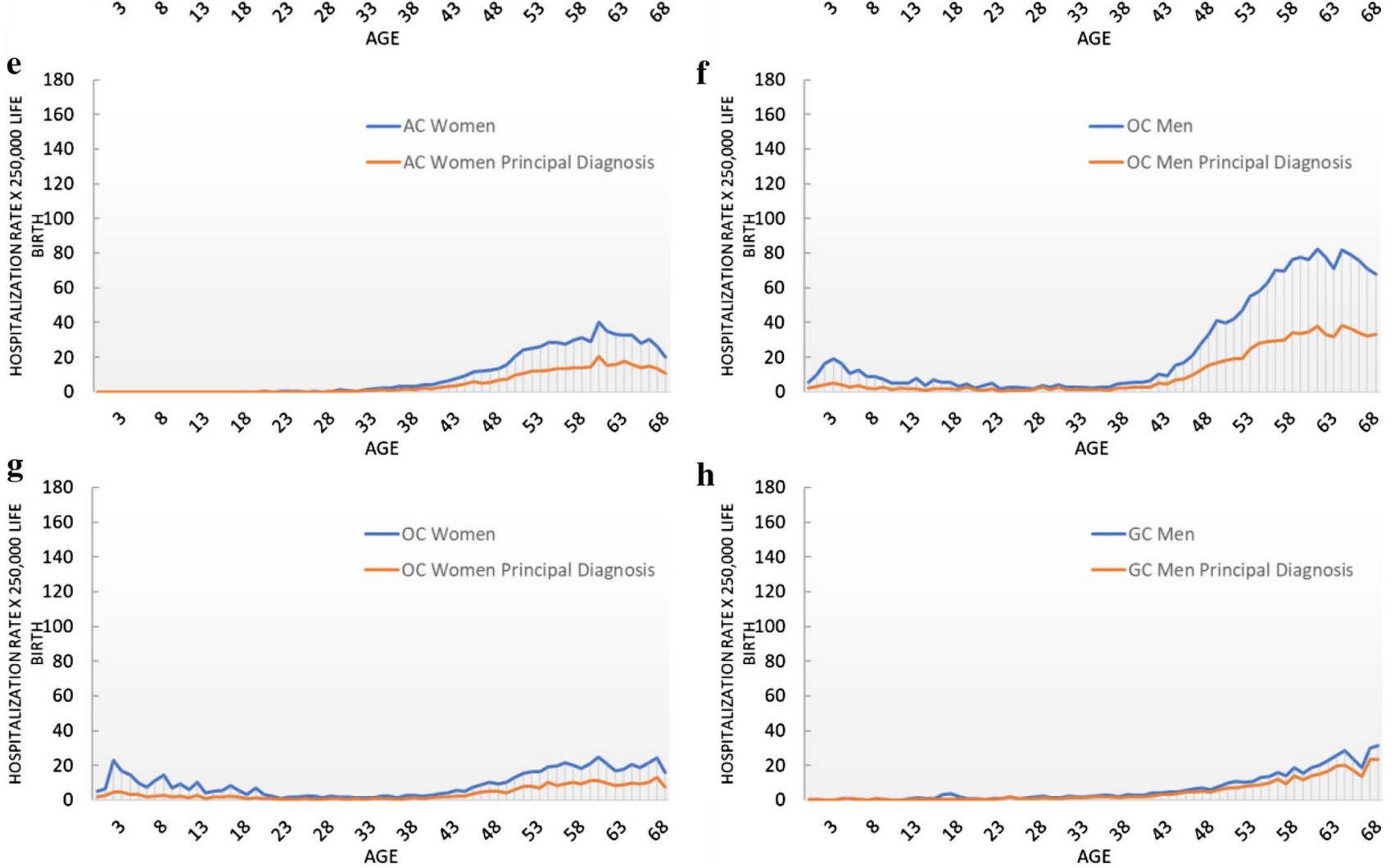

Fig. 1 Hospitalization rate by age per 250,000 live births (primary or secondary diagnosis and primary diagnosis only). $G W$ genital warts, $C I N$ cervical intraepithelial neoplasia, $A C$ anal cancer, $O C$ oropharyngeal cancer, $G C$ genital cancer

1996 (not vaccinable) and after 1997 (vaccinable - the first cohort that was offered vaccination starting from 2008) were strongly different. The vaccinable cohort registered lower hospitalization rates for all comparable ages $(-61 \%$ and $-67 \%$ between 17 and 21 years old for GW and CIN, respectively). These reductions demonstrate the first effect of the 

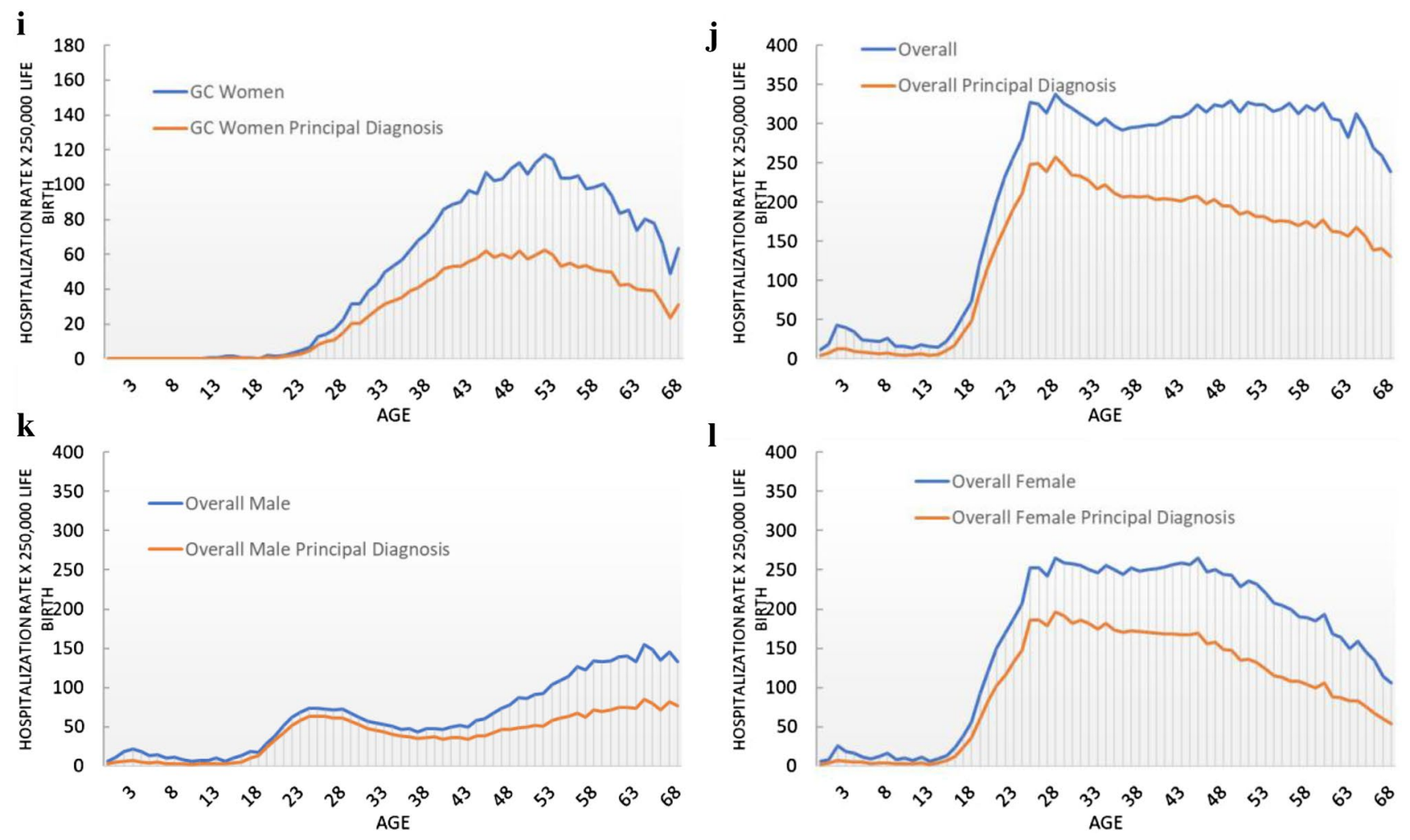

Fig. 1 (continued)

Table 1 Lifetime hospitalization cost per 250,000 live births distributed by inclusion criteria classification

\begin{tabular}{|c|c|c|c|}
\hline & Women & Men & Total \\
\hline \multicolumn{4}{|c|}{ a. Primary or secondary diagnosis inclusion criteria } \\
\hline Genital warts & $€ 2.772 .884$ & $€ 1.909 .803$ & $€ 4.682 .687$ \\
\hline CIN & $€ 5.311 .117$ & & $€ 5.311 .117$ \\
\hline Anal cancer & $€ 3.595 .604$ & $€ 3.515 .654$ & $€ 7.111 .257$ \\
\hline Oropharyngeal cancer & $€ 3.947 .230$ & $€ 10.149 .871$ & $€ 14.097 .101$ \\
\hline Genital cancer & $€ 18.267 .346$ & $€ 1.895 .647$ & $€ 20.162 .993$ \\
\hline Total & $€ 33.894 .181$ & $€ 17.470 .974$ & $€ 51.365 .155$ \\
\hline \multicolumn{4}{|c|}{ b. Primary diagnosis inclusion criteria } \\
\hline Genital warts & $€ 720.770$ & $€ 1.597 .477$ & $€ 2.318 .247$ \\
\hline CIN & $€ 3.264 .413$ & & $€ 3.264 .413$ \\
\hline Anal cancer & $€ 1.724 .001$ & $€ 1.856 .338$ & $€ 3.580 .340$ \\
\hline Oropharyngeal cancer & $€ 1.584 .460$ & $€ 6.908 .219$ & $€ 8.492 .678$ \\
\hline Genital cancer & $€ 10.133 .276$ & $€ 1.366 .860$ & $€ 11.500 .136$ \\
\hline Total & $€ 17.426 .920$ & $€ 11.728 .893$ & $€ 29.155 .814$ \\
\hline
\end{tabular}

Italian public prevention strategy adopted in Italy against the HPV-related diseases during 2008-2012 [12].

In 2017, the Italian NHS had an average annual expenditure of $€ 38.3$ million for the acquisition of the anti-HPV vaccine for the vaccination strategy between 2008 and 2018 [31]. If this investment leads to a hospitalization risk reduction for $\mathrm{GC}, \mathrm{CIN}$, and $\mathrm{GW}$ (similar association to HPV) in both sexes as estimated in this analysis, Italian NHS savings only for these hospitalisations cost conditions around $€ 19.7$ million (38\% of the total lifetime hospitalization cost and $51 \%$ of the vaccination prevention strategy investment). These savings could increase when the efficacy of the Hpv9 vaccination strategies are observable for $\mathrm{AC}$ and $\mathrm{OC}$, demonstrating not only a very high impact in terms of morbidity and mortality [13] but also an efficient investment in terms of public health decisions [12, 18, 19].

The present study has several limitations. First, real-world data from administrative archives were only available for hospitalization at the national level, and published Italian sources of cost data were limited. The use of hospitalization data sources may have a high impact on the underestimation of the lifetime economic burden due to the lack of DRG tariff updates in the Italian context. Furthermore, no estimation was made in terms of drug, outpatient, and indirect costs. However, due to the increased number of outpatient management of these diseases (especially for GW) and the high impact of cancers on the productivity aspects of the diagnosed patients, we can assume that the economic burden estimated in this work represents just one-third of the total impact from the social perspective [12, 18, 27, 32-34].

A second limitation refers to the estimation of the vaccination effect on the GW for women. We can assume that the 
Table 2 Hospitalization cost per 250,000 live births

\begin{tabular}{lll}
\hline & Observed cost 10-21 years & Lifetime cost \\
\hline GW women overall & $€ 432,497$ & $€ 2,772,884$ \\
GW women not vaccinated & $€ 495,729$ & $€ 2,836,116$ \\
GW women vaccinated & $€ 190,464$ & $€ 1,154,654^{*}$ \\
Not vaccinated-Vaccinated & $€ 305,265$ & $€ 1,681,462$ \\
& Observed cost 10-21 years & Lifetime cost \\
CIN women overall & $€ 153,310$ & $€ 5,311,117$ \\
CIN women not vaccinated & $€ 173,414$ & $€ 5,331,188$ \\
CIN women vaccinated & $€ 60,197$ & $€ 1,741,231^{*}$ \\
Not vaccinated-Vaccinated & $€ 113,217$ & $€ 3,589,957$ \\
& Observed cost 10-21 years & Lifetime cost \\
GW/CIN women overall & $€ 585,807$ & $€ 8,084,001$ \\
GW/CIN women not vaccinated & $€ 669,143$ & $€ 2,167,304$ \\
GW/CIN women vaccinated & $€ 250,661$ & $€ 5,271,419$ \\
Not vaccinated-vaccinated & $€ 418,482$ &
\end{tabular}

$G W$ genital warts, $C I N$ cervical intraepithelial neoplasia, $A C$ anal cancer, $O C$ oropharyngeal cancer, $G C$ genital cancer

*Assuming the same average risk reduction for all ages after 21 years a - Hospitalisation rates for the registered cohort $\mathrm{GW}$

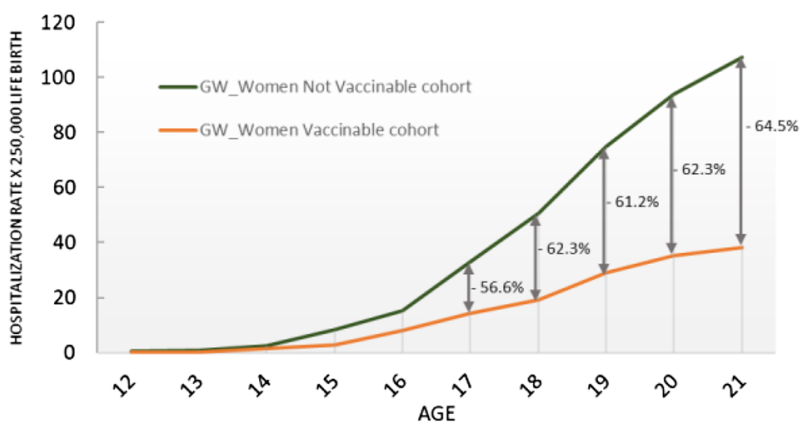

$\mathrm{b}$ - Hospitalisation rates for the registered cohort and forecast for vaccinated cohort $\mathrm{GW}$

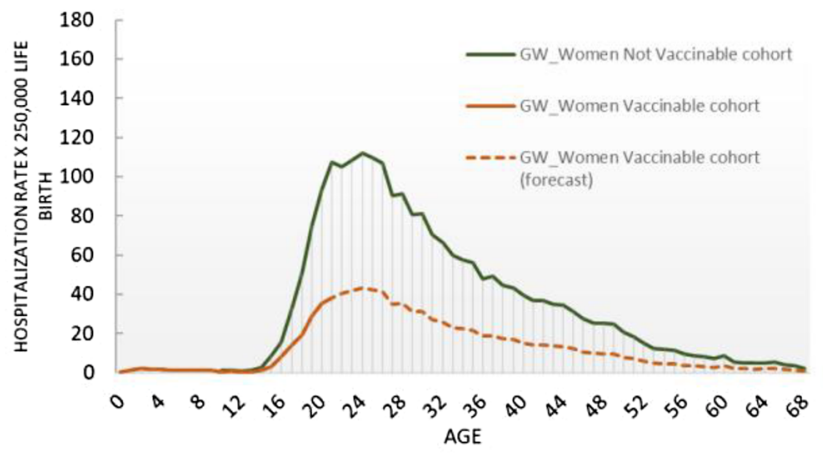

\section{c - Hospitalisation rates for the registered cohort CIN}

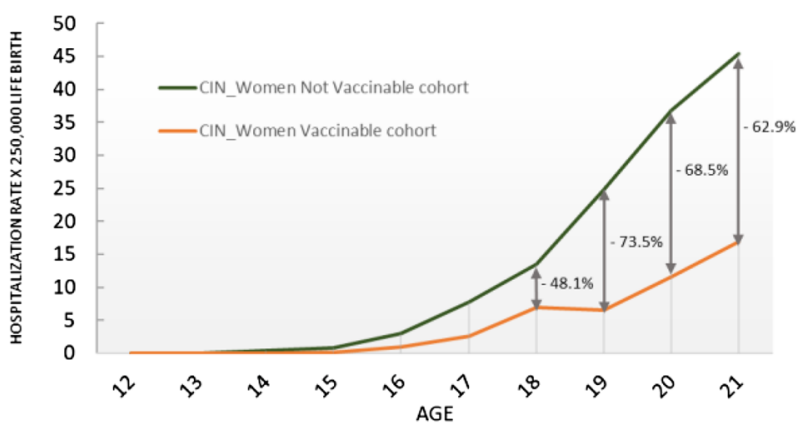

$\mathrm{d}$ - Hospitalisation rates for the registered cohort and forecast for vaccinated cohort CIN

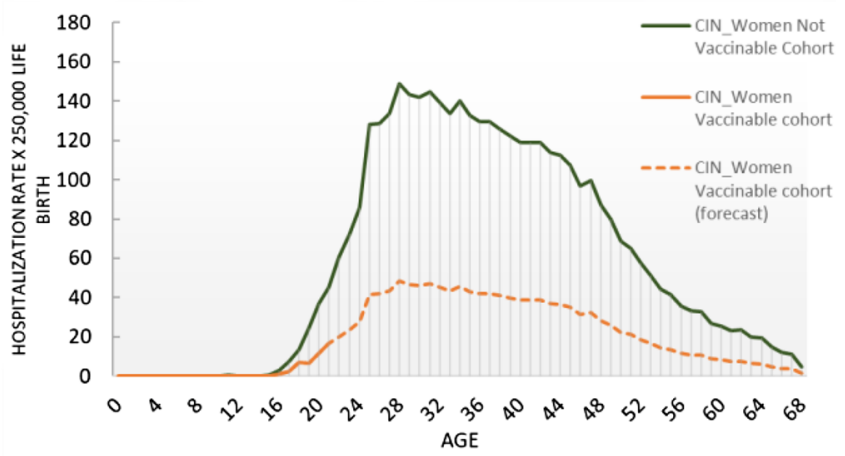

Fig. 2 Hospitalization rate per 250,000 live births-GW women vaccinated and not vaccinated cohort. $G W$ genital warts, $C I N$ cervical intraepithelial neoplasia

hospitalization reduction registered for vaccinable cohorts (born after 2017) in Italy is the combination of three main drivers: (1) time, (2) efficacy of the vaccine, and (3) vaccine active offer. The first variable reflects the changes in terms 
of management of the disease during the years considered (inpatient vs outpatient management). In Italy, the hospitalization rate has decreased for many years, and this is particularly true for the GW and CIN considered cases in younger ages ( $-40 \%$ on average between the period 2006-2008 and 2016-2018). This difference was also expected for the management of GW for men. However, in this case, no difference was registered in terms of hospitalization reduction between the corresponding two cohorts of boys (born after or before 2017). Moreover, the hospitalization reduction is also a function of the efficacy of the vaccine that reflects the coverage rate of the different cohorts considered in the analysis and the mix of bivalent and quadrivalent vaccines used for these cohorts (bivalent vaccine has no immunization HPV 6 and 9 that are related to GW). Finally, age represents the variable that reflects the effect of primary preventive strategies. The vaccinable cohort registered $-62 \%$ of hospitalization during the ages between 16 and 21, demonstrating the first indicative effects of the public health intervention proposed in Italy between 2006 and 2011.

These limitations should be considered in future research; however, in our opinion, they do not undermine the validity of the estimates in the present study or their estimated impact on the total lifetime economic burden of HPV-related diseases. Future research should address these gaps in epidemiological and cost data to reduce the uncertainty associated with the present estimates and evaluate the real effects for cancer diseases.

\section{Conclusion}

This study represents the first economic analysis that estimates the effects of anti-HPV vaccination preventive strategies in Italy based on real-world data. Similar analyses have investigated only the burden of disease reduction attributable to HPV vaccine introduction according to the literature data $[35,36]$.

This work is one of the first analyses to evaluate the effects of anti-HPV interventions based on real-world data. It is hoped that these results can be reconfirmed over time through the continuous monitoring of hospitalisations for GWs of the vaccinated cohort but also confirmed for HPVrelated diseases whose incidence occurs at an older age.

In light of the results, it can be concluded that not vaccinating against a preventable disease represents a cost. Failure to vaccinate leads to persistent avoidable costs due to avoidable hospitalisations and deaths. Prevention interventions also supported by their cost-effectiveness rationale should be offered in a timely and comprehensive way to the population to prove their positive economic impact.
Author contributions AM and FSM designed the study, conducted the analysis, and finalized the draft of the manuscript. AM, FSM, and GF provided guidance on the methodology, reviewed the results, and critically assessed the manuscript. AM and PS managed the data and performed statistical analysis. All the authors provided data and/or reviewed the results of the final draft of the manuscript. All authors approved the final version of the manuscript.

Funding Open access funding provided by Università degli Studi di Roma Tor Vergata within the CRUI-CARE Agreement.

\section{Declarations}

Conflict of interest The authors declare no conflict of interest.

Open Access This article is licensed under a Creative Commons Attribution 4.0 International License, which permits use, sharing, adaptation, distribution and reproduction in any medium or format, as long as you give appropriate credit to the original author(s) and the source, provide a link to the Creative Commons licence, and indicate if changes were made. The images or other third party material in this article are included in the article's Creative Commons licence, unless indicated otherwise in a credit line to the material. If material is not included in the article's Creative Commons licence and your intended use is not permitted by statutory regulation or exceeds the permitted use, you will need to obtain permission directly from the copyright holder. To view a copy of this licence, visit http://creativecommons.org/licenses/by/4.0/.

\section{References}

1. Goldstone, S., Palefsky, J.M., Giuliano, A.R., Moreira, E.D., Aranda, C., Jessen, H., Hillman, R.J., Ferris, D.G., Coutlee, F., Liaw, K.L., Marshall, J.B., Zhang, X., Vuocolo, S., Barr, E., Haupt, R.M., Guris, D., Garner, E.I.: Prevalence of and risk factors for human papillomavirus (HPV) infection among HIV-seronegative men who have sex with men. J. Infect. Dis. 203, 66-74 (2011)

2. McQuillan, G., Kruszon-Moran, D., Markowitz, L.E., Unger, E.R., Paulose-Ram, R.: Prevalence of HPV in Adults Aged 18-69: United States, 2011-2014. NCHS Data Brief. 2017 Apr;(280):1-8. PMID: 28463105

3. Brotherton, J.M., Fridman, M., May, C.L., Chappell, G., Saville, A.M., Gertig, D.M.: Early effect of the HPV vaccination programme on cervical abnormalities in Victoria, Australia: an ecological study. Lancet 377, 2085-2092 (2011)

4. Mariani, L., Vici, P., Suligoi, B., Checcucci-Lisi, G., Drury, R.: Early direct and indirect impact of quadrivalent HPV (4HPV) vaccine on genital warts: a systematic review. Adv. Ther. 32, 10-30 (2015)

5. Nygard, M., Saah, A., Munk, C., Tryggvadottir, L., Enerly, E., Hortlund, M., Sigurdardottir, L.G., Vuocolo, S., Kjaer, S.K., Dillner, J.: Evaluation of the long-term anti-human Papillomavirus 6 (HPV6), 11, 16, and 18 immune responses generated by the quadrivalent HPV vaccine. Clin. Vaccine Immunol. 22, 943-948 (2015)

6. Guan, P., Howell-Jones, R., Li, N., Bruni, L., de Sanjose, S., Franceschi, S., Clifford, G.M.: Human papillomavirus types in 115,789 HPV-positive women: a meta-analysis from cervical infection to cancer. Int. J. Cancer 131, 2349-2359 (2012)

7. Chaturvedi, A.K.: Beyond cervical cancer: burden of other HPVrelated cancers among men and women. J. Adolesc. Health 46, S20-S26 (2010) 
8. Koutsky, L.A., Galloway, D.A., Holmes, K.K.: Epidemiology of genital human papillomavirus infection. Epidemiol. Rev. 10, 122-163 (1988)

9. Armstrong, L.R., Derkay, C.S., Reeves, W.C.: Initial results from the national registry for juvenile-onset recurrent respiratory papillomatosis. RRP Task Force. Arch. Otolaryngol. Head. Neck. Surg. 125(7), 743-748 (1999)

10. Armstrong, L.R., Preston, E.J., Reichert, M., Phillips, D.L., Nisenbaum, R., Todd, N.W., Jacobs, I.N., Inglis, A.F., Manning, S.C., Reeves, W.C.: Incidence and prevalence of recurrent respiratory papillomatosis among children in Atlanta and Seattle. Clin. Infect. Dis. 31, 107-109 (2000)

11. Audisio, R.A., Icardi, G., Isidori, A.M., Liverani, C.A., Lombardi, A., Mariani, L., Mennini, F.S., Mitchell, D.A., Peracino, A., Pecorelli, S., Rezza, G., Signorelli, C., Rosati, G.V., Zuccotti, G.V.: Public health value of universal HPV vaccination. Crit. Rev. Oncol. Hematol. 97, 157-167 (2016)

12. Ministero della Salute: Piano nazionale prevenzione vaccinale 2017. National immunization Program 2017. http://www.salute. gov.it/imgs/C_17_pubblicazioni_2571_allegato.pdf (2018). Accessed Jan 2020

13. Marcellusi, A.: Impact of HPV vaccination: health gains in the Italian female population. Popul. Health Metr. 15, 36 (2017)

14. Marcellusi, A., Capone, A., Favato, G., Mennini, F.S., Baio, G., Haeussler, K., Bononi, M.: HPV Italian Collaborative Study Group. Health utilities lost and risk factors associated with HPV-induced diseases in men and women: the HPV Italian collaborative study group. Clin. Ther. 37(1), 156-167.e4 (2015)

15. Costa, S., Venturoli, S., Mennini, F.S., Marcellusi, A., Pesaresi, M., Leo, E., Falasca, A., Marra, E., Cricca, M., Santini, D., Zerbini, M., Pelusi, G.: Population-based frequency assessment of HPV-induced lesions in patients with borderline Pap tests in the Emilia-Romagna Region: the PATER study. Curr. Med. Res. Opin. 27, 569-578 (2011)

16. Mennini, F.S., Fabiano, G., Marcellusi, A., Sciattella, P., Saia, M., Cocchio, S., Baldo, V.: Burden of disease of human papillomavirus (HPV): hospitalizations in the marche and veneto regions. An observational study. Clin. Drug Investig. 38, 173180 (2018)

17. Mennini, F.S., Fabiano, G., Favato, G., Sciattella, P., Bonanni, P., Pinto, C., Marcellusi, A.: Economic burden of HPV9-related diseases: a real-world cost analysis from Italy. Eur. J. Health Econ. 20, 829-840 (2019)

18. Mennini, F.S., Bonanni, P., Bianic, F., de Waure, C., Baio, G., Plazzotta, G., Uhart, M., Rinaldi, A., Largeron, N.: Cost-effectiveness analysis of the nine-valent HPV vaccine in Italy. Cost Eff. Resour. Alloc. 15, 11 (2017)

19. Mariani, L., Bonanni, P., Castiglia, P., Chiamenti, G., Conforti, G., Conversano, M., Icardi, G., Maio, T., Mennini, F., Prato, R., Scotti, S., Signorelli, C., Zuccotti, G.V.: Prevention of HPV cancer related through HPV-9: state of the art, potential benefits and open issues. Ig. Sanita Pubbl. 71, 629-650 (2015)

20. Mennini, F.S., Costa, S., Favato, G., Picardo, M.: Anti-HPV vaccination: a review of recent economic data for Italy. Vaccine 27(Suppl 1), A54-A61 (2009)

21. Haeussler, K., Marcellusi, A., Mennini, F.S., Favato, G., Picardo, M., Garganese, G., Bononi, M., Costa, S., Scambia, G., Zweifel, P., Capone, A., Baio, G.: Cost-effectiveness analysis of universal human papillomavirus vaccination using a dynamic bayesian methodology: the BEST II study. Value Health 18, 956-968 (2015)

22. Favato, G., Baio, G., Capone, A., Marcellusi, A., Costa, S., Garganese, G., Picardo, M., Drummond, M., Jonsson, B., Scambia, G., Zweifel, P., Mennini, F.S.: Novel health economic evaluation of a vaccination strategy to prevent HPV-related diseases: the BEST study. Med. Care 50, 1076-1085 (2012)
23 Istituto Nazionale di Statistica (ISTAT): Resident population in Italy per year and age. http://demo.istat.it/ (2018)

24. Suligoi, B., Vittori, G., Salfa, M.C., Timelli, L., Corsini, D., Fattorini, G., Mariani, L.: Genital Warts 2 Working Group: prevalence and incidence of external genital warts in a sample of Italian general femalepopulation. BMC Infect. Dis. 17, 126 (2017)

25. Newsholme, A., Stevenson, T.H.: The Graphic method of constructing a life table illustrated by the Brighton life table, 18911900. J. Hyg. (Lond) 3, 297-324 (1903)

26. Wunsch, G., Mouchart, M., Duchêne, J.: The life table : modelling survival and death. In: Carlson, E.D., Gietel-Basten, S. (eds.) European Studies of Population, p. 306. Springer, Dordrecht (2010)

27. Baio, G., Capone, A., Marcellusi, A., Mennini, F.S., Favato, G.: Economic burden of human papillomavirus-related diseases in Italy. PLoS One. 2012;7(11):e49699. https://doi.org/10.1371/ journal.pone.0049699. Epub 2012 Nov 21. Erratum in: PLoS One. 2013 Sep 27;8(9):null. PMID: 23185412; PMCID: PMC3504125

28. Centers for Disease Control and Prevention: Genital HPV infection-CDC fact sheet. Centers for Disease Control and Prevention (2015)

29. Eurocare Survival of Cancer Patient in Europe. Istituto Nazionale Tumori Istituto Superiore di Sanità (2015)

30. Global Burden of Disease Cancer Collaboration, Fitzmaurice, C., Abate, D., Abbasi, N., Abbastabar, H., Abd-Allah, F., Abdel-Rahman, O., Abdelalim, A., Abdoli, A., Abdollahpour, I., Abdulle, A.S.M., Abebe, N.D., Abraha, H.N., Abu-Raddad, L.J., Abualhasan A., Adedeji, I.A., Advani, S.M., Afarideh, M., Afshari, M., Aghaali, M., Agius, D., Agrawal, S., Ahmadi, A., Ahmadian, E., Ahmadpour, E., Ahmed, M.B., Akbari, M.E., Akinyemiju, T., Al-Aly, Z., AlAbdulKader, A.M., Alahdab, F., Alam, T., Alamene, G.M., Alemnew, B.T.T., Alene, K.A., Alinia, C., Alipour, V., Aljunid, S.M., Bakeshei, F.A., Almadi, M.A.H., Almasi-Hashiani, A., Alsharif, U., Alsowaidi, S., Alvis-Guzman, N., Amini, E., Amini, S., Amoako, Y.A., Anbari, Z., Anber, N.H., Andrei, C.L., Anjomshoa, M., Ansari, F., Ansariadi, A.,Appiah, S.C.Y., Arab-Zozani, M., Arabloo, J., Arefi, Z., Aremu, O., Areri, H.A., Artaman, A., Asayesh, H., Asfaw, E.T., Ashagre, A.F., Assadi, R., Ataeinia, B., Atalay, H.T., Ataro, Z., Atique, S., Ausloos, M., Avila-Burgos, L., Avokpaho, E.F.G.A., Awasthi, A., Awoke, N., Ayala, Quintanilla, B.P., Ayanore, M.A., Ayele, H.T., Babaee, E., Bacha, U., Badawi, A., Bagherzadeh, M., Bagli, E., Balakrishnan, S., Balouchi, A., Bärnighausen, T.W., Battista, R.J., Behzadifar, M., Behzadifar, M., Bekele, B.B., Belay, Y,B., Belayneh, Y.M., Berfield, K.K.S., Berhane, A., Bernabe, E., Beuran, M., Bhakta, N., Bhattacharyya, K., Biadgo, B., Bijani, A., Bin Sayeed, M.S., Birungi C., Bisignano, C., Bitew, H., Bjørge, T., Bleyer, A., Bogale, K.A., Bojia, H.A., Borzì, A.M., Bosetti, C., Bou-Orm, I.R., Brenner, H., Brewer, J.D., Briko, A.N., Briko, N,I., Bustamante-Teixeira, M.T., Butt, Z.A., Carreras, G., Carrero, J.J., Carvalho, F., Castro, C., Castro, F., Catalá-López F., Cerin, E., Chaiah, Y., Chanie, W.F., Chattu, V.K., Chaturvedi, P., Chauhan, N.S., Chehrazi, M., Chiang, P.P., Chichiabellu, T.Y., Chido-Amajuoyi O.G, Chimed-Ochir, O., Choi, J.J., Christopher, D.J., Chu, D.T., Constantin, M.M., Costa, V.M., Crocetti, E., Crowe, C.S., Curado, M.P., Dahlawi, S.M.A., Damiani, G., Darwish, A.H., Daryani, A., das Neves, J., Demeke, F.M., Demis A.B., Demissie, B.W., Demoz, G.T., Denova-Gutiérrez, E., Derakhshani, A., Deribe, K.S., Desai, R., Desalegn, B.B., Desta, M., Dey, S., Dharmaratne, S.D., Dhimal, M., Diaz, D., Dinberu M.T.T., Djalalinia, S., Doku, D.T., Drake, T.M., Dubey, M., Dubljanin, E., Duken, E.E., Ebrahimi, H., Effiong, A., Eftekhari, A., El Sayed, I., Zaki MES., El-Jaafary, S.I., El-Khatib, Z., Elemineh, D.A., Elkout, H., Ellenbogen, R.G., Elsharkawy, A., Emamian, M.H., Endalew, D.A., Endries, A.Y., Eshrati, B., Fadhil, I., Fallah Omrani, V., Faramarzi, M., Farhangi, M.A., Farioli, A., Farzadfar, F., Fentahun, N., Fernandes, E., Feyissa, G.T., Filip, I., Fischer, F., Fisher, J.L., Force, 
L.M., Foroutan, M., Freitas, M., Fukumoto, T., Futran, N.D, Gallus, S., Gankpe, F.G., Gayesa, R.T., Gebrehiwot, T.T., Gebremeskel, G.G., Gedefaw, G.A., Gelaw, B.K., Geta, B., Getachew, S., Gezae, K.E., Ghafourifard, M., Ghajar, A., Ghashghaee, A., Gholamian, A., Gill, P.S., Ginindza, T.T.G., Girmay, A., Gizaw, M., Gomez, R.S, Gopalani, S.V., Gorini, G., Goulart, B.N.G., Grada, A., Ribeiro Guerra, M., Guimaraes, A.L.S., Gupta, P.C., Gupta, R., Hadkhale, K., Haj-Mirzaian, A., Haj-Mirzaian, A., Hamadeh, R.R., Hamidi, S., Hanfore, L.K., Haro, J.M., Hasankhani, M., Hasanzadeh, A., Hassen, H.Y., Hay, R.J., Hay, S.I., Henok, A., Henry, N.J., Herteliu, C., Hidru, H.D., Hoang, C.L., Hole, M.K., Hoogar, P., Horita, N., Hosgood, H.D., Hosseini, M., Hosseinzadeh, M., Hostiuc, M., Hostiuc, S., Househ, M., Hussen, M.M., Ileanu, B., Ilic, M.D., Innos, K., Irvani, S.S.N., Iseh, K.R., Islam, S.M.S., Islami, F., Jafari Balalami, N., Jafarinia M., Jahangiry, L., Jahani, M.A., Jahanmehr, N., Jakovljevic, M., James, S.L., Javanbakht, M., Jayaraman, S., Jee, S.H., Jenabi, E., Jha, R.P., Jonas, J,B., Jonnagaddala, J., Joo, T., Jungari, S.B., Jürisson, M., Kabir, A., Kamangar, F., Karch, A., Karimi, N., Karimian, A., Kasaeian, A., Kasahun, G.G., Kassa, B., Kassa, T.D., Kassaw, M.W., Kaul, A., Keiyoro, P.N., Kelbore, A.G., Kerbo, A.A., Khader, Y.S., Khalilarjmandi, M., Khan, E.A., Khan, G., Khang, Y.H., Khatab, K., Khater, A., Khayamzadeh, M., Khazaee-Pool, M., Khazaei, S., Khoja, A.T., Khosravi, M.H., Khubchandani, J., Kianipour, N., Kim, D., Kim, Y.J., Kisa, A., Kisa, S., Kissimova-Skarbek, K., Komaki, H., Koyanagi A., Krohn, K.J., Bicer, B.K., Kugbey, N., Kumar, V., Kuupiel, D., La Vecchia, C., Lad, D.P., Lake, E.A., Lakew, A.M., Lal, D.K., Lami, F.H., Lan, Q., Lasrado, S., Lauriola, P., Lazarus, J.V, Leigh, J., Leshargie, C.T., Liao, Y., Limenih, M.A., Listl, S., Lopez, A.D., Lopukhov, P.D., Lunevicius, R., Madadin, M., Magdeldin, S., El Razek, H.M.A., Majeed, A., Maleki, A., Malekzadeh, R., Manafi, A., Manafi, N., Manamo, W.A., Mansourian, M., Mansournia, M.A., Mantovani, L.G., Maroufizadeh, S., Martini, S.M.S., Mashamba-Thompson, T.P., Massenburg, B.B., Maswabi, M.T., Mathur, M.R., McAlinden, C., McKee, M., Meheretu, H.A.A., Mehrotra, R., Mehta, V., Meier, T., Melaku, Y.A., Meles, G.G., Meles, H.G., Melese, A., Melku, M., Memiah, P.T.N., Mendoza, W., Menezes, R.G., Merat, S., Meretoja, T.J., Mestrovic, T., Miazgowski, B., Miazgowski, T., Mihretie, K.M.M., Miller, T.R., Mills, E.J., Mir, S.M., Mirzaei, H., Mirzaei, H.R., Mishra, R., Moazen, B., Mohammad, D.K., Mohammad, K.A., Mohammad, Y., Darwesh, A.M., Mohammadbeigi, A., Mohammadi, H., Mohammadi., M., Mohammadian, M., Mohammadian-Hafshejani, A., Mohammadoo-Khorasani, M., Mohammadpourhodki, R., Mohammed, A.S., Mohammed, J.A., Mohammed, S., Mohebi, F., Mokdad, A.H., Monasta, L., Moodley, Y., Moosazadeh, M., Moossavi, M., Moradi, G., Moradi-Joo, M., Moradi-Lakeh, M., Moradpour, F., Morawska, L., Morgado-daCosta, J., Morisaki, N., Morrison, S.D., Mosapour, A., Mousavi, S.M., Muche, A.A., Muhammed, O.S.S., Musa, J., Nabhan, A.F., Naderi, M., Nagarajan, A.J., Nagel, G., Nahvijou, A., Naik, G., Najafi. F., Naldi, L., Nam, H.S., Nasiri, N., Nazari. J., Negoi, I., Neupane, S., Newcomb, P.A., Nggada, H.A., Ngunjiri, J.W., Nguyen, C.T., Nikniaz., L., Ningrum, D.N.A., Nirayo, Y.L., Nixon, M.R., Nnaji, C.A., Nojomi, M., Nosratnejad, S., Shiadeh, M.N., Obsa, M.S., Ofori-Asenso, R., Ogbo, F.A., Oh, I.H., Olagunju, A.T., Olagunju, T.O., Oluwasanu, M.M., Omonisi, A.E., Onwujekwe, O.E., Oommen, A.M., Oren, E., Ortega-Altamirano, D.D.V., Ota, E., Otstavnov, S.S., Owolabi, M.O., P A M, Padubidri, J.R., Pakhale, S., Pakpour, A.H., Pana, A., Park, E.K., Parsian, H., Pashaei, T., Patel, S., Patil, S.T., Pennini, A., Pereira, D.M., Piccinelli, C., Pillay, J.D., Pirestani, M., Pishgar, F., Postma, M.J., Pourjafar, H., Pourmalek, F., Pourshams, A., Prakash, S., Prasad, N., Qorbani, M., Rabiee, M., Rabiee, N., Radfar, A., Rafiei, A., Rahim, F., Rahimi M, Rahman M.A., Rajati, F., Rana, S.M., Raoofi, S., Rath, G.K., Rawaf, D.L., Rawaf, S., Reiner, R.C., Renzaho, A.M.N., Rezaei, N., Rezapour, A., Ribeiro, A.I., Ribeiro, D., Ronfani, L., Roro, E.M., Roshandel, G., Rostami, A., Saad, R.S.,
Sabbagh, P., Sabour, S., Saddik, B., Safiri, S., Sahebkar, A., Salahshoor, M.R., Salehi, F., Salem, H., Salem, M.R., Salimzadeh, H., Salomon, J.A., Samy, A.M., Sanabria, J., Santric Milicevic, M.M., Sartorius, B., Sarveazad, A., Sathian, B., Satpathy, M., Savic, M., Sawhney, M., Sayyah, M., Schneider, I.J.C., Schöttker, B., Sekerija, M., Sepanlou, S.G., Sepehrimanesh, M., Seyedmousavi, S., Shaahmadi, F., Shabaninejad, H., Shahbaz, M., Shaikh, M.A., Shamshirian, A., Shamsizadeh, M., Sharafi, H., Sharafi, Z., Sharif, M., Sharifi, A., Sharifi, H., Sharma, R., Sheikh, A., Shirkoohi, R., Shukla, S.R., Si, S., Siabani, S., Silva, D.A.S., Silveira, D.G.A., Singh, A., Singh, J.A., Sisay, S., Sitas, F., Sobngwi, E., Soofi, M., Soriano J.B., Stathopoulou, V., Sufiyan MB., Tabarés-Seisdedos, R., Tabuchi, T., Takahashi, K., Tamtaji, O.R., Tarawneh, M.R., Tassew ,S.G., Taymoori, P., Tehrani-Banihashemi, A., Temsah, M.H., Temsah, O., Tesfay, B.E, Tesfay, F.H., Teshale, M.Y., Tessema, G.A., Thapa, S., Tlaye, K.G., Topor-Madry, R., TovaniPalone, M.R., Traini, E., Tran, B.X., Tran, K.B., Tsadik, A.G., Ullah, I., Uthman, O.A., Vacante, M., Vaezi, M., Varona Pérez, P., Veisani, Y., Vidale, S., Violante, F.S., Vlassov, V., Vollset, S.E., Vos, T., Vosoughi, K., Vu, G.T., Vujcic, I.S., Wabinga, H., Wachamo, T.M., Wagnew, F.S., Waheed, Y., Weldegebreal, F., Weldesamuel, G.T., Wijeratne, T., Wondafrash, D.Z., Wonde, T.E., Wondmieneh, A.B., Workie, H.M., Yadav, R., Yadegar, A., Yadollahpour, A., Yaseri, M., Yazdi-Feyzabadi, V., Yeshaneh, A., Yimam, M.A., Yimer, E.M., Yisma, E., Yonemoto, N., Younis, M.Z., Yousefi, B., Yousefifard, M., Yu, C., Zabeh, E., Zadnik, V., Moghadam, T.Z., Zaidi Z., Zamani, M., Zandian, H., Zangeneh, A., Zaki, L., Zendehdel, K., Zenebe, Z.M., Zewale, T.A., Ziapour, A., Zodpey, S., Murray, C.J.L.: Global, regional, and national cancer incidence, mortality, years of life lost, years lived with disability, and disability-adjusted life-years for 29 cancer groups, 1990 to 2017: a systematic analysis for the global burden of disease study. JAMA Oncol. 2019 Dec 1;5(12):1749-1768. https://doi.org/10. 1001/jamaoncol.2019.2996. Erratum in: JAMA Oncol. 2020 Mar 1;6(3):444. Erratum in: JAMA Oncol. May 1;6(5):789. Erratum in: JAMA Oncol. Mar 1;7(3):466. PMID: 31560378; PMCID: PMC6777271

31. Italian Medicines Agency (Agenzia Italiana del Farmaco-AIFA): The use of medicines in Italy-national report-Year 2018. Pensiero scientifico editore, Rome, Italy (2018)

32. Marcellusi, A., Fabiano, G., Viti, R., Francesa Morel, P.C., Nicolò, G., Siracusano, A., Mennini, F.S.: Economic burden of schizophrenia in Italy: a probabilistic cost of illness analysis. BMJ Open 8(2):e018359. https://doi.org/10.1136/bmjopen-2017-018359 (2018)

33. Marcellusi, A., Viti, R., Capone, A., Mennini, F.S.: The economic burden of HCV-induced diseases in Italy. A probabilistic cost of illness model. Eur. Rev. Med. Pharmacol. Sci. 19(9), 1610-1620 (2015)

34. Marcellusi, A., Viti, R., Mecozzi, A., Mennini, F.S.: The direct and indirect cost of diabetes in Italy: a prevalence probabilistic approach. Eur. J. Health Econ. 17, 139-147 (2016)

35. Cocchio, S., Bertoncello, C., Baldovin, T., Fonzo, M., Bennici, S.E., Buja, A., Majori, S., Baldo, V.: Awareness of HPV and drivers of HPV vaccine uptake among university students: a quantitative, cross-sectional study. Health Soc. Care Community (2020). https://doi.org/10.1111/hsc. 12974

36. Cocchio, S., Baldovin, T., Bertoncello, C., Buja, A., Furlan, P., Saia, M., Baldo, V.: Decline in hospitalization for genital warts in the Veneto region after an HPV vaccination program: an observational study. BMC Infect. Dis. 17, 249 (2017)

Publisher's Note Springer Nature remains neutral with regard to jurisdictional claims in published maps and institutional affiliations. 